\title{
Tetracycline Reduces Kidney Damage Induced by Loxosceles Spider Venom
}

\author{
Cinthya Kimori Okamoto ${ }^{1}$, Carmen W. van den Berg ${ }^{2}$, Mizuno Masashi ${ }^{3}$, \\ Rute M. Gonçalves-de-Andrade ${ }^{1}$ and Denise V. Tambourgi ${ }^{1, *}$ \\ 1 Immunochemistry Laboratory, Butantan Institute, São Paulo 05503-900, Brazil; \\ cinthya.okamoto@butantan.gov.br (C.K.O.); rutemga2@gmail.com (R.M.G.-d.-A.) \\ 2 Institute of Molecular and Experimental Medicine, School of Medicine, Cardiff University, Cardiff CF144XN, \\ UK; vandenbergcw@cardiff.ac.uk \\ 3 Renal Replacement Therapy, Nagoya University Graduate School of Medicine, Nagoya 466-8550, Japan; \\ mmizu@med.nagoya-u.ac.jp \\ * Correspondence: denise.tambourgi@butantan.gov.br; Tel.: +55-11-26279727
}

Academic Editor: Eivind Undheim

Received: 15 December 2016; Accepted: 23 February 2017; Published: 2 March 2017

\begin{abstract}
Envenomation by Loxosceles spider can result in two clinical manifestations: cutaneous and systemic loxoscelism, the latter of which includes renal failure. Although incidence of renal failure is low, it is the main cause of death, occurring mainly in children. The sphingomyelinase D (SMase D) is the main component in Loxosceles spider venom responsible for local and systemic manifestations. This study aimed to investigate the toxicity of L. intermedia venom and SMase D on kidney cells, using both in vitro and in vivo models, and the possible involvement of endogenous metalloproteinases (MMP). Results demonstrated that venom and SMase D are able to cause death of human kidney cells by apoptosis, concomitant with activation and secretion of extracellular matrix metalloproteases, MMP-2 and MMP-9. Furthermore, cell death and MMP synthesis and secretion can be prevented by tetracycline. In a mouse model of systemic loxoscelism, Loxosceles venom-induced kidney failure was observed, which was abrogated by administration of tetracycline. These results indicate that MMPs may play an important role in Loxosceles venom-induced kidney injury and that tetracycline administration may be useful in the treatment of human systemic loxoscelism.
\end{abstract}

Keywords: Loxosceles venom; sphingomyelinase D; kidney cells; matrix metalloproteinases (MMPs); kidney injury; tetracycline

\section{Introduction}

Envenomation by Loxosceles spider is considered a serious public health problem in Brazil, with more than 7000 cases being reported annually [1]. Loxoscelism can be presented as two clinical forms: cutaneous and systemic. Local pain, fever, erythema and edema are characteristic manifestations of cutaneous loxoscelism, which may lead to ischemia evolving to necrosis [2-4]. Systemic loxoscelism is less common, with the highest incidence in children [2]. Symptoms can include fever, thrombocytopenia, intravascular hemolysis, platelet aggregation, persistent inflammation, and in severe cases, kidney failure and death [2,5].

Various studies have identified several of the components present in Loxosceles venom that may contribute to the pathology, including lipases, hyaluronidase, collagenase, sphingomyelinases and phosphatases [2,6]. In a series of studies, we have purified, characterized, cloned and expressed sphingomyelinases D (SMase D) from Loxosceles venoms [7]. We have shown that these toxins are the main components responsible for the cutaneous and systemic effects, including the induction of complement-dependent hemolysis, as well as the development of dermonecrotic lesions [7]. 
Loxosceles SMase D hydrolyzes sphingomyelin thereby generating ceramide-1-phosphate (C1P or $\mathrm{N}$-acyl-sphingosine-1-phosphate) [8-10]. At low concentrations, C1P stimulates cell proliferation and inhibits apoptosis, whereas at relatively high concentrations it induces cell death by apoptosis [11]. Furthermore, Loxosceles SMase D can, in the presence of $\mathrm{Mg}^{2+}$, catalyze the release of choline from lysophosphatidylcholine (LPC), but not from phosphatidylcholine [12]. LPC is an abundant phospholipid in plasma, where it is tightly bound to albumin. Removal of its choline headgroup yields lysophosphatidic acid (LPA), a potent lipid mediator with numerous biological activities in many different cell types [13,14].

Our previous studies showed that development of the dermonecrotic lesion is associated with the induction and activation of matrix metalloproteinases (MMPs) $[15,16]$. In vitro and in vivo analysis showed that SMases D induced an increase in the expression of MMP-2 and MMP-9, decreased keratinocyte cell viability by apoptosis and increased the inflammatory infiltrate of neutrophils at the lesion site $[15,16]$. Moreover, the application of MMP inhibitors, such as tetracycline, doxycycline and minocycline, in in vitro and in vivo experimental models of cutaneous loxoscelism, inhibited the development of the skin lesion, concomitant with the inhibition of MMPs expression/secretion and keratinocyte apoptosis $[16,17]$.

Various studies have shown the involvement of MMP-2 and MMP-9 in acute and chronic models of kidney injury, induced by ischemia-reperfusion injury, leading to glomerular damage, fibrosis and decline of renal function [18-20]. Tetracyclines have been used in the treatment of infectious diseases and are currently used in the treatment of diseases in which there is a participation of MMPs, such as osteoarthritis, ischemia, inflammation and cancer [21-24]. Tetracyclines inhibit MMPs by blocking the activity of the mature form, by chelation of zinc atoms from the active site, inhibition of maturation of pro-MMPs and reducing their expression [24,25].

The mechanism by which Loxosceles envenomation can cause kidney failure, one of the main pathologic aspects of systemic loxoscelism, is not fully understood. Using a murine model, we previously showed that animals injected with Loxosceles venom or SMase D, developed acute tubular necrosis with deposition of eosinophilic material in the proximal and distal tubules [26]. Edema, presence of erythrocytes in the extracellular space and vacuolar degeneration in the proximal and distal tubules, have also been described [27]. Some studies suggested that hemoglobinuria caused by Loxosceles envenomation can be an important component of the renal damage, by reducing circulation and leading to tubular necrosis [28]. Moreover, in vitro assays using the MDCK kidney cell line showed loss of cell viability upon treatment with SMase $\mathrm{D}$, indicating direct toxicity of this toxin on kidney cells $[29,30]$. However, in vivo experiments using mice injected with $L$. gaucho venom demonstrated that kidney failure occurs due to renal vasoconstriction and intrarenal rhabdomyolysis and not directly by cytotoxicity [31].

Thus, considering that the mechanisms leading to renal failure in systemic loxoscelism is not fully elucidated and considering the important role of MMPs in the cutaneous loxoscelism as well as in various renal pathologies, the aim of this study was to investigate the role of extracellular MMPs in Loxosceles venom and SMase D induced renal cell damage. The potential of tetracycline in the control of venom induced renal pathology in vivo was also investigated.

\section{Results}

\subsection{Loxosceles Venom and SMase D Induce Renal Cell Death by Apoptosis}

To evaluate the toxicity of Loxosceles venom and SMase D, human HK-2 renal cells were incubated with venom or toxin and the cell viability was analyzed by the MTT method. Figure 1 shows that Loxosceles venom induced a significant loss of HK-2 cell viability after $72 \mathrm{~h}$ of treatment (Figure 1A). The SMase D was more potent than the venom, inducing cell death at 5 and $10 \mu \mathrm{g}$ and at all times tested. After $48 \mathrm{~h}, 2.5 \mu \mathrm{g}$ of SMase D also caused a significant decrease in cell viability. At $72 \mathrm{~h}$ of treatment, SMase D induced 100\% cell death in all doses tested (Figure 1B). 


\section{A: Venom}

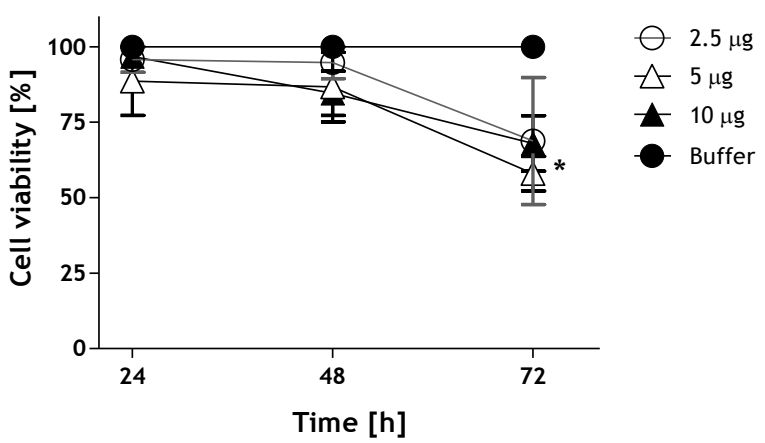

\section{B: SMase}

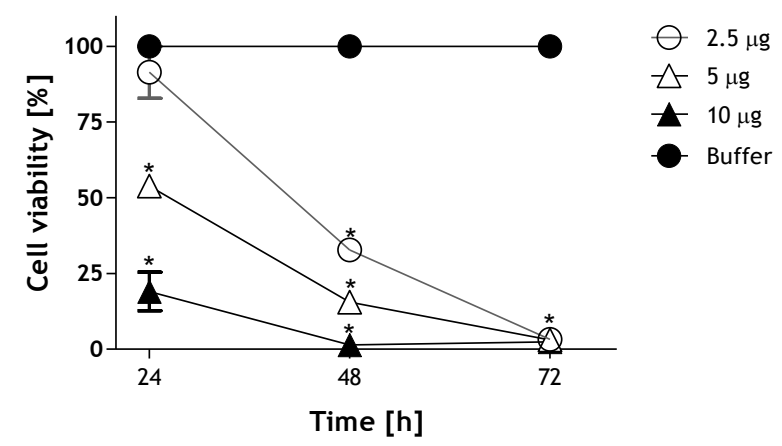

C: Caspase 3 activity

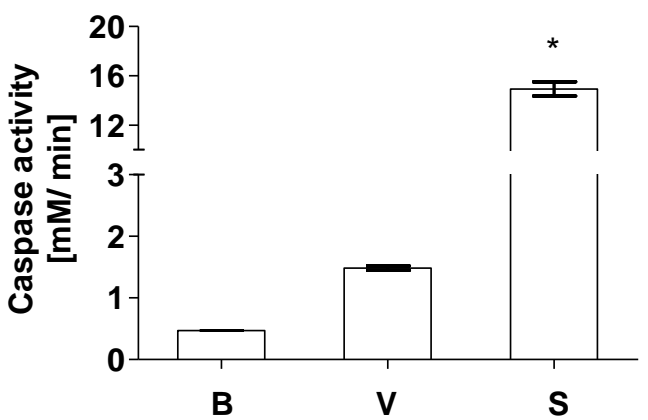

Figure 1. Toxicity of Loxosceles venom and SMase D on kidney cells. Viability: HK-2 cell cultures $\left(5 \times 10^{4}\right.$ cells) were incubated with increasing concentrations of Loxosceles venom (V) (A) or SMase D (S) (B). After 24, 48 and $72 \mathrm{~h}$ of treatment, cell viability was analyzed by the MTT assay. Caspase-3 activation: HK-2 cells $\left(10^{6}\right)$ were incubated with $10 \mu \mathrm{g} / 200 \mu \mathrm{L}$ total volume of venom or SMase D or Phosphate-buffered saline-PBS (B) for $3 \mathrm{~h}$ and the activity of Caspase-3 was analyzed in cell lysates (C). Results are representative of three independent experiments and expressed as the mean of duplicates \pm standard deviation. Significant differences $\left({ }^{*}\right) p<0.05$ from the control (buffer treated cells).

In order to verify if the loss of cell viability induced by venom and SMase D occurred by apoptosis, HK-2 cells were incubated for $2 \mathrm{~h}$ with buffer, venom or SMase D $\left(10 \mu \mathrm{g} / 10^{6}\right.$ cells $)$ and the supernatants analyzed for caspase- 3 activity. Figure $1 \mathrm{C}$ shows that SMase D caused a significant caspase-3 activation, which was 10 times higher than that induced by whole venom, confirming that venom and SMase D both induced apoptosis. 


\subsection{MMP Secretion by HK-2 Cells}

To examine the involvement of metalloproteases in systemic loxoscelism, samples of supernatants of HK-2 cells treated with various concentrations of Loxosceles venom or SMase D or buffer were collected at 24, 48 and $72 \mathrm{~h}$ and subjected to zymography. Figure 2 shows that cells treated with 2.5 and $5 \mu \mathrm{g}$ of SMase D induced an increase in the secretion of active MMP-9 protein (Mr $\sim 85 \mathrm{kDa})$, at all time points when compared to untreated cells. Cells treated with venom showed higher secretion of MMP-9 after 48 and $72 \mathrm{~h}$. Supernatants collected after $72 \mathrm{~h}$ of treatment with venom or SMase D, showed an increase in the secretion of a gelatinase with a $\mathrm{Mr}$ of around $70 \mathrm{kDa}$, corresponding to MMP-2 (Figure 2).
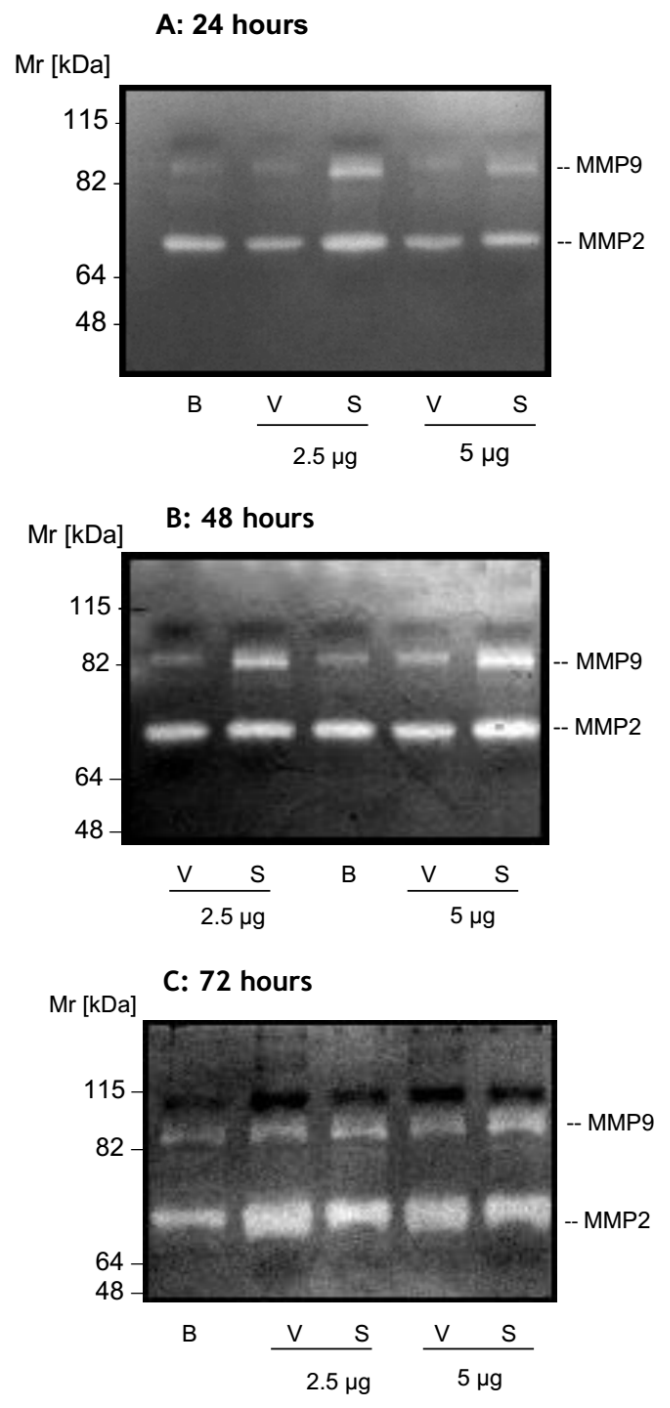

Figure 2. Loxosceles venom and SMase D induce the secretion of gelatinases in HK-2 cells. HK-2 cell culture supernatants collected after 24 (A), 48 (B) and $72 \mathrm{~h}(\mathrm{C})$ of treatment with Loxosceles venom (V) or SMase D (S) were run on gelatin containing 10\% SDS-PAGE gels under non-reducing conditions. Control supernatants (B) were recovered at the same incubation periods from cells incubated with medium plus Phosphate-buffered saline-PBS (B).

\subsection{Tetracycline Prevents Venom and SMase D Increased Expression of MMPs and Protects Kidney Cells} from Death

To assess whether tetracycline affected viability of human kidney cells, HK-2 cells were incubated with different concentrations of tetracycline and the viability was determined at 24,48 and $72 \mathrm{~h}$ by 
the MTT method. Figure 3A shows that tetracycline at high concentrations $(50 \mu \mathrm{g} / \mathrm{mL})$ is toxic to kidney cells, causing loss of cell viability. At concentrations of $30 \mu \mathrm{g} / \mathrm{mL}$ tetracycline and lower, only a small reduction in cell viability was observed. In order to evaluate the possible protective effect of this inhibitor on cell death induced by the toxin and the venom, cells were incubated with SMase D or Loxosceles venom $(5 \mu \mathrm{g})$ in the presence or absence of tetracycline $(20 \mu \mathrm{g})$. Figure 3 (panels B and C) shows that the tetracycline treatment significantly prevented cell death induced by both venom and SMase D. This inhibition positively correlated with a significant decrease in the secretion of MMP-2 and MMP-9 as shown by zymography analysis (Figure 4).
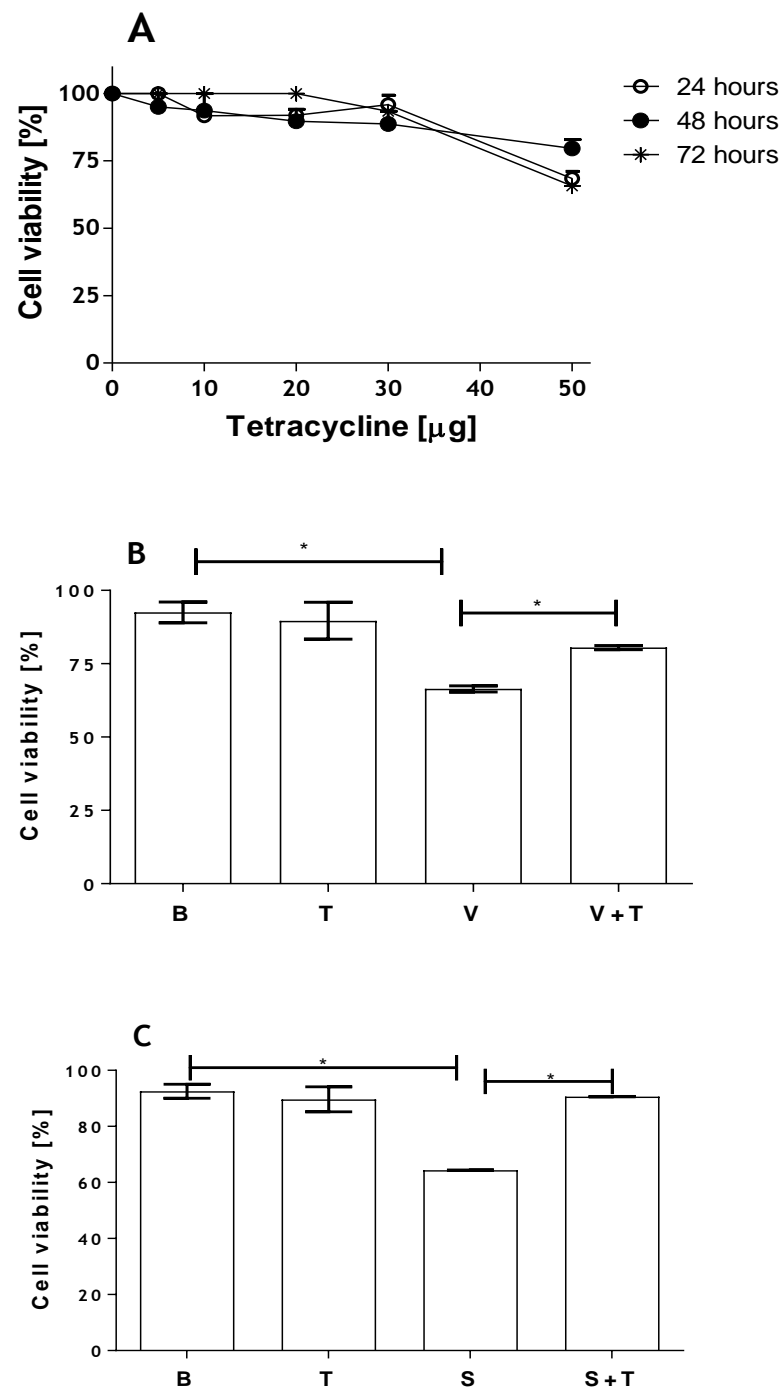

Figure 3. Tetracycline inhibits Loxosceles venom and SMase D induced cell death in HK-2 cells. HK-2 cell cultures $\left(5 \times 10^{4}\right.$ cells) were incubated with increasing concentrations of tetracycline and cell viability was assessed at 24,48 and $72 \mathrm{~h}$ by the MTT method $(\mathbf{A})$; HK-2 cell cultures $\left(5 \times 10^{4}\right.$ cells) were incubated with venom (V) (B) or SMase D (S) (C) from L. intermedia (5 $\mu \mathrm{g} / 200 \mu \mathrm{L}$ total volume), and treated or not with tetracycline $(\mathrm{T})[20 \mu \mathrm{g} / \mathrm{mL}$ ]. Analyses were performed after $48 \mathrm{~h}$ of incubation. All assays were performed in duplicate. Results are representative of three independent experiments and expressed as the mean of duplicates \pm standard deviation. Significant differences $\left(^{*}\right) p<0.05$. 
$\mathrm{Mr}[\mathrm{kDa}]$
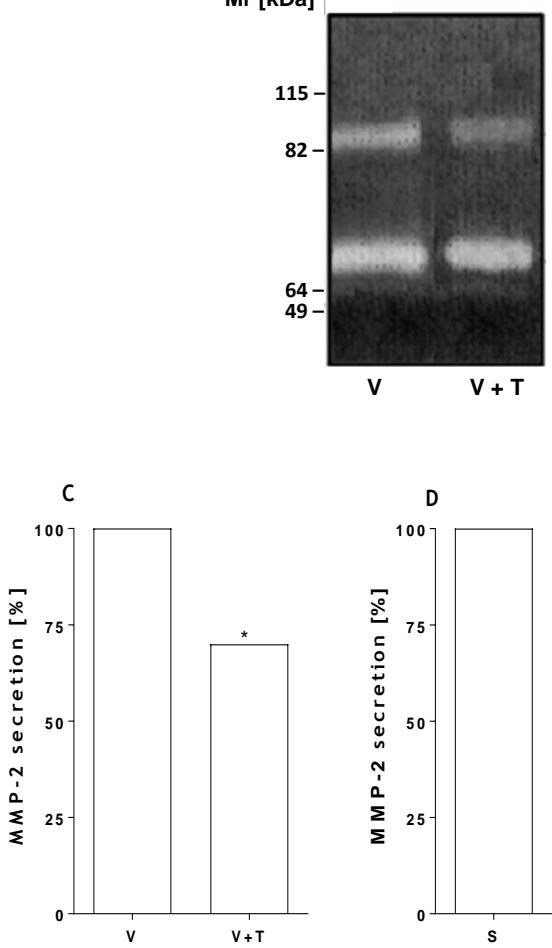

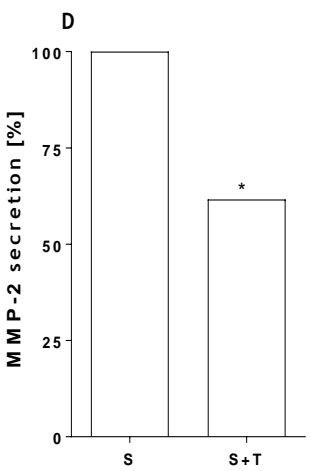

B
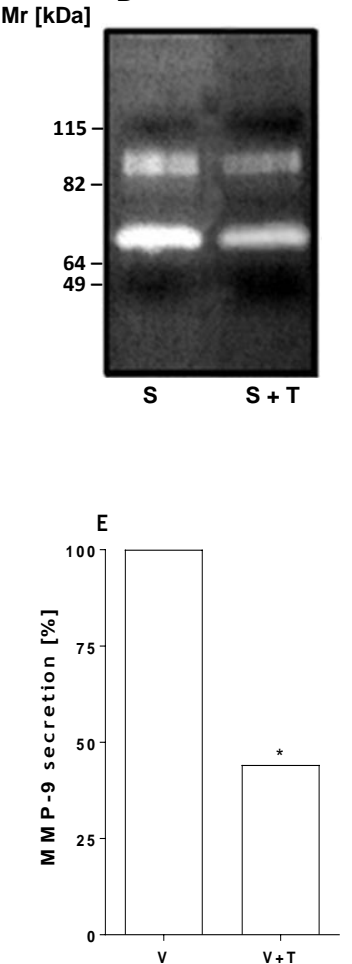

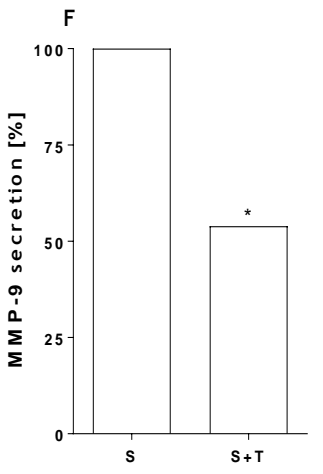

Figure 4. Tetracycline inhibits Loxosceles venom and SMase D induced MMPs. HK-2 cell cultures $\left(5 \times 10^{4}\right.$ cells) were incubated with venom $(\mathrm{V})(\mathbf{B})$ or SMase D (S) (C) from L. intermedia $(5 \mu \mathrm{g} / 200 \mu \mathrm{L}$ total volume), and treated or not with tetracycline $(\mathrm{T})[20 \mu \mathrm{g} / \mathrm{mL}]$. Supernatants of the HK-2 cells were collected after $48 \mathrm{~h}$ of incubation and submitted to zymography (A, B) followed by densitometry analyses $(\mathbf{C}-\mathbf{F})$. Significant differences $\left(^{*}\right) p<0.05$.

\subsection{Loxosceles Venom and SMase D Induce an Increase in MMP Gene Expression in HK-2 Cells}

As shown in Figures 2 and 4, both venom and SMase D from Loxosceles induced increased secretion of MMPs by HK-2 cells. To verify if this increase of MMPs protein activity in the HK-2 cells culture supernatants was due to increased expression rather than just increased secretion of these proteases, mRNA expression of the MMPs was assessed. Furthermore, the action of tetracycline on the expression of the gelatinases was also evaluated.

Figure 5 (panels A and B) shows that venom and SMase D increased the mRNA expression of both MMP-2 and MMP-9 in HK-2 cells. Tetracycline on its own also increased the levels of mRNA expression of both MMPs, although not to the same level as the venom or SMase D. Co-incubation of the HK-2 cells with tetracycline and venom/SMase D prevented the venom/SMase D-induced increase in mRNA expression. The mRNA expression of $\beta$-actin was not affected by treatment with tetracycline, venom or SMase D. Figure 5C shows densitometric analysis of the MMPs expression; values were normalized with constitutive $\beta$ actin expression. 
A

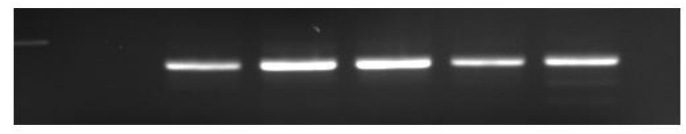

MMP-2

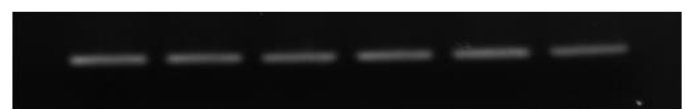

B-actin

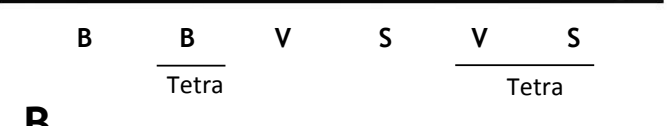

B

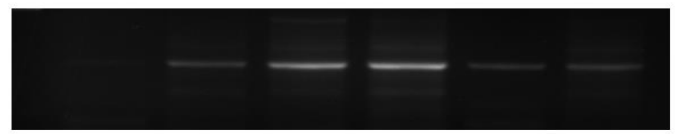

MMP-9

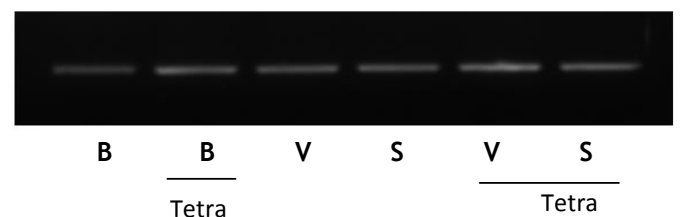

B - actin

C
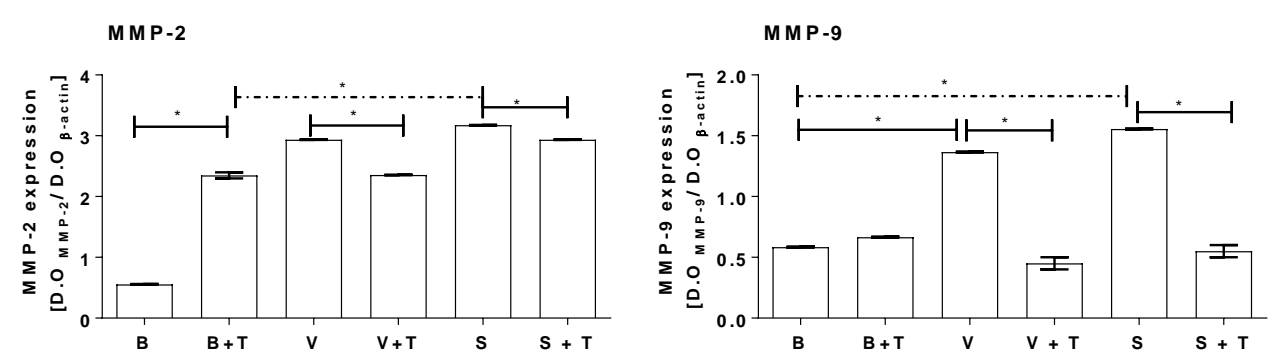

Figure 5. Tetracycline reduces MMP-2 and MMP-9 gene expression induced by Loxosceles venom and SMase D. HK-2 cell cultures $\left(5 \times 10^{4}\right.$ cells) were incubated with venom (V: $12.5 \mu \mathrm{g} / 200 \mu \mathrm{L}$ total volume) (A) or SMase D (S: $6.25 \mu \mathrm{g} / 200 \mu \mathrm{L}$ total volume) (B) from L. intermedia and treated or not with tetracycline (T: $20 \mu \mathrm{g} / \mathrm{mL}$ ). Cells treated with Phosphate-buffered saline-PBS (B) were used as negative control. MMP-2 and MMP-9 specific mRNA expression was analyzed at $48 \mathrm{~h}$ by RT-PCR. As control, mRNA expression of $\beta$-actin was assessed; (C) Densitometry analyses of MMP-2 and MMP-9 bands. Significant differences $\left(^{*}\right) p<0.05$.

\subsection{Tetracycline Prevents Loxosceles Venom Induced Renal Injury in Mice}

To evaluate the effect of tetracycline in renal injury in vivo, BALB/c mice were i.d. injected with Loxosceles venom. After $30 \mathrm{~min}$, the animals were i.p. treated with tetracycline, which was repeated twice at intervals of $4 \mathrm{~h}$. Control mice were injected with PBS or tetracycline only. After $24 \mathrm{~h}$, the animals were euthanized and the kidneys collected for histological analysis. Figure 6 shows that kidneys obtained from control mice injected with PBS only and treated or not with tetracycline showed a normal pattern of renal tubules and renal corpuscles. Animals injected with venom showed dilation of the renal tubules, presence of hyaline material in the tubular and glomerular regions, and erythrocyte extravasation in the vascular region. Analysis of the tubular region showed significant interstitial injuries as loss of brush border and/or destruction of tubular structure. Changes could also be observed in the glomerular areas with fibrin exudation, thrombi formation, mesangiolysis and intraor extracellular proliferation. The tetracycline treatment considerably reduced the renal injury induced 
by the venom, although some damage was still observed in the medullary region as indicated by the arrow (Figure 6).

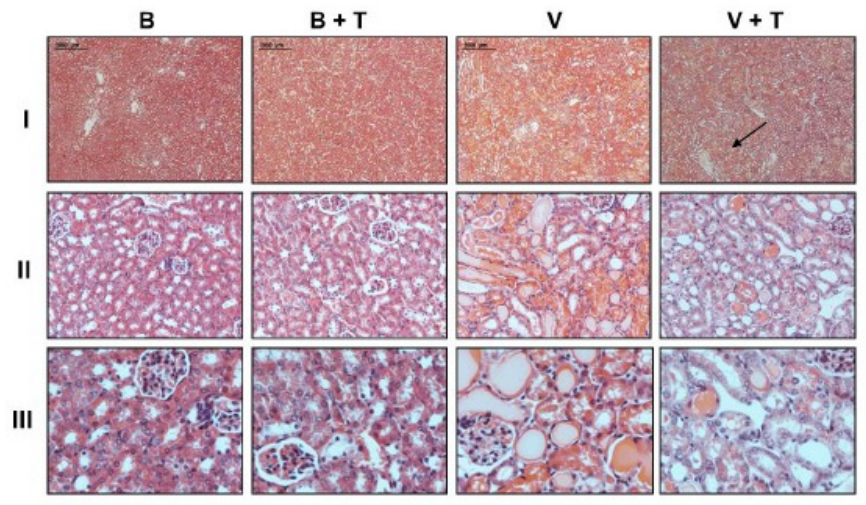

(A)

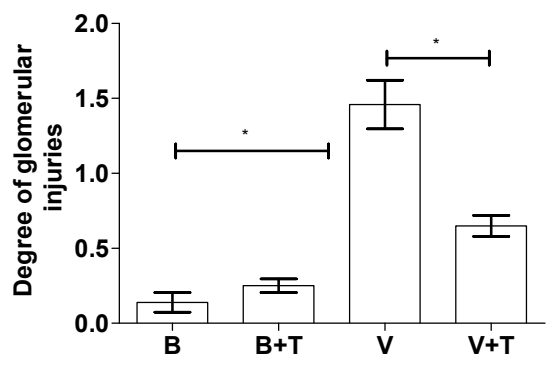

(B)

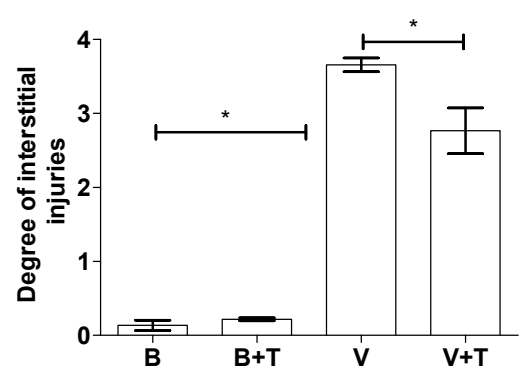

(C)

Figure 6. Histological analysis of the renal lesions induced by Loxosceles venom after tetracycline treatment. BALB/c mice were injected with $4.8 \mu \mathrm{g}$ of venom (V) and, after $30 \mathrm{~min}$, treated three times every $4 \mathrm{~h}$ with $200 \mu \mathrm{L}$ of tetracycline $(\mathrm{T})(5 \mathrm{mg} / \mathrm{mL})$. Control animals were injected with Phosphate-buffered saline-PBS (B). After $24 \mathrm{~h}$, the animals were euthanized and the kidneys collected for histological analysis. (A) Photos correspond to the sections of the kidney stained by H/E. Bars of $2000 \mu \mathrm{m}, 1000 \mu \mathrm{m}$ and $100 \mu \mathrm{m}$ for lines I, II and III, respectively. Arrow shows the medullary region; Estimation of glomerular injuries (B) and interstitial changes (C) of the histological samples. Results are representative of two independent experiments and expressed as the mean of triplicates \pm standard deviation. Significant differences $\left(^{*}\right) p<0.05$.

Serum and urine samples from the same mice were collected for biochemical analysis. As shown in Figure 7 venom induced a significant increase of creatinine and protein in the urine and a significant increase of urea and a significant decrease of albumin in the serum samples, as compared to control animals injected with buffer or buffer plus tetracycline. The treatment of mice with tetracycline reduced the venom-induced changes of creatinine and protein in the urine and of urea in the serum, but not of albumin in the serum. 
A

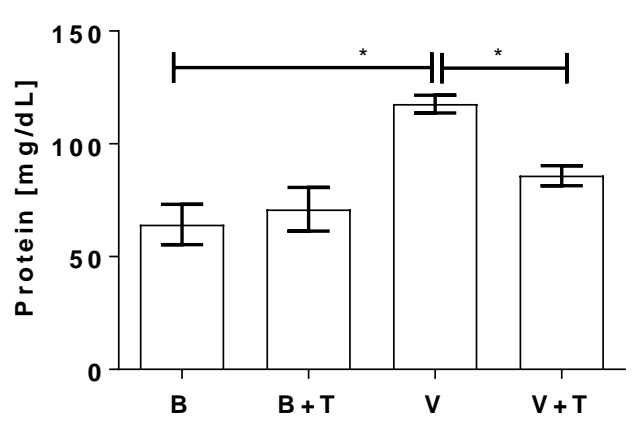

C

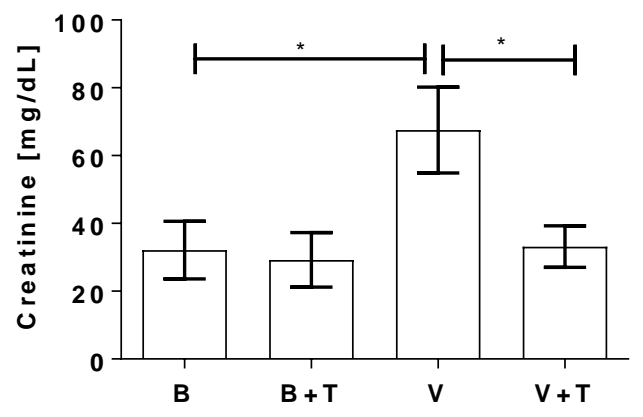

B

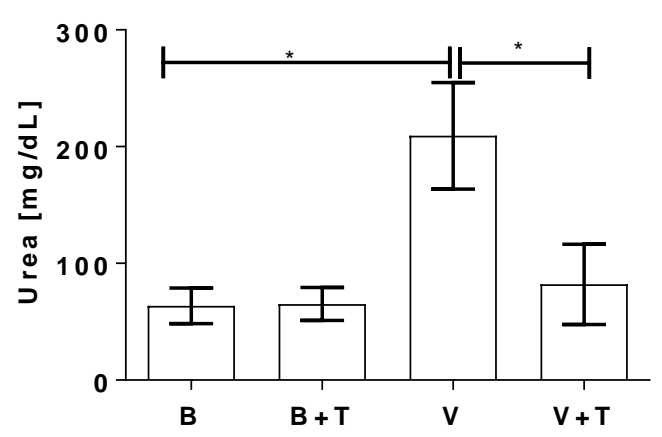

D

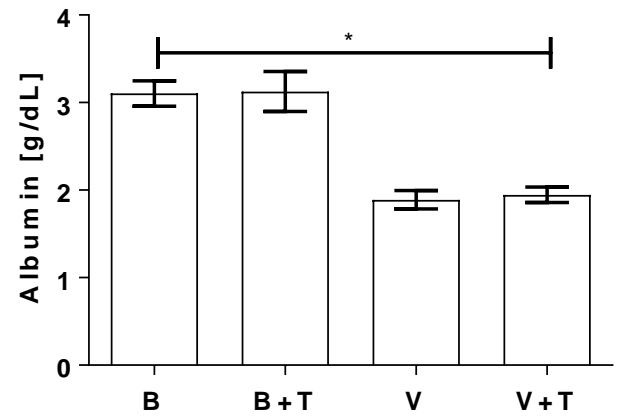

Figure 7. Biochemical analysis of serum and urine from Loxosceles venom and tetracycline treated group. BALB/c mice were injected with $9.6 \mu \mathrm{g}$ of venom and, after $30 \mathrm{~min}$, treated three times every $4 \mathrm{~h}$ with $200 \mu \mathrm{L}$ of tetracycline [ $5 \mathrm{mg} / \mathrm{mL}$ ]. Control animals were injected with Phosphate-buffered saline-PBS (B). Urine samples, collected from each animal during $24 \mathrm{~h}$ of the treatments, were analyzed for the presence of protein (A) and creatinine (B). Serum samples, collected $24 \mathrm{~h}$ after buffer/venom injection, were analyzed for the presence of urea (C) and albumin (D). Results are representative of two independent experiments and expressed as the mean of triplicates \pm standard deviation. Significant differences $\left(^{*}\right) p<0.05$.

\section{Discussion}

Envenomation by spiders of the Loxosceles genus can cause severe cases kidney failure and death. It is well accepted that SMase D is the main venom component responsible for most of the clinical aspects observed in loxoscelism. We have previously shown that both the venom and SMase D of Loxosceles are capable of inducing loss of viability of human keratinocytes [16].

Similar to the data obtained in studies using canine kidney cells (MDCK) [32], in the present study we demonstrate that L. intermedia venom is toxic to human kidney cells (HK-2), causing 30\%-40\% cell death after $72 \mathrm{~h}$ of treatment. The SMase D was more toxic, causing 100\% cell death with only $5 \mu \mathrm{g}$ of protein after $48 \mathrm{~h}$. After $72 \mathrm{~h}$ incubation, 100\% cell death at all concentrations of SMase D was observed, indicating that the toxic action of SMase D may contribute to the development of the renal damage.

The matrix metalloproteases (MMPs) belong to a family of zinc-dependent endopeptidases secreted or bound to the cell membrane, which can be classified into several subgroups, such as collagenase, elastase, gelatinase, and matrilysins metalloproteases. They are capable of hydrolyzing a variety of proteins, including, extracellular matrix components such as collagen and fibronectin and cell surface molecules [33-35]. Increase of MMPs in inflammatory renal disease leads to the degradation of the extracellular matrix [36]. MMPs are also reported to be associated with other nephropathies such as proteinuria, loss of membrane selectivity, increased glomerular fibrosis and renal epithelium $[27,37,38]$.

In previous studies, we have demonstrated in an in vivo rabbit model of dermonecrosis and in in vitro using human keratinocytes (HaCaT cells), that venom and SMase D from L. intermedia 
induced increased secretion of MMPs (MMP-2 and MMP-9) and that this directly correlated with the loss of cell viability by apoptosis [15-17]. The results obtained in the present study showed that both venom and SMase D are also able to induce an increase in the expression and secretion of endogenous metalloproteinases MMP-2 and MMP-9, as well as activation of caspase-3 in the human proximal tubular cell line HK-2. Apoptosis is an important mechanism leading to cell death, which is initially characterized by a series of morphological changes, DNA fragmentation and exposure of phosphatidylserine on the cell surface [39]. The activation of caspase-3, a protein belonging to the family of cysteine proteases that cleaves substrates with aspartate residues, plays a central role in the programmed cell death [40]. The results obtained here suggest that the HK-2 cell death induced by venom/SMase D from Loxosceles occurs by an apoptotic process.

Our previous in vitro studies, using human keratinocytes, showed that tetracycline inhibits the toxic action of the venom and SMases D on cell viability, and also prevents the venom and SMase D increased secretion of MMP-2 and MMP-9 [16]. Using rabbits as model of cutaneous loxoscelism we showed that the topical use of tetracycline significantly reduced the dermonecrotic lesion induced by Loxosceles venom or SMase D. This result correlated with a decreased expression/secretion of MMPs at the injection site of toxins [17]. In the present study using the renal cell line HK-2, we show that tetracycline significantly reduced the venom and SMase D-induced HK-2 cell death and inhibited the venom/SMase D increased expression and secretion of MMPs, as demonstrated by PCR and zymography analyses. Although tetracycline itself seems to induce some toxicity, this was compensated for by its ability to completely prevent the much higher toxicity induced by the venom or SMase D.

Interestingly, it was recently demonstrated that the bioactive sphingolipid ceramide 1-phosphate $(\mathrm{C} 1 \mathrm{P})$, one of the products of SMase D catalytic activity on cell membrane sphingomyelin [8-10], is able to upregulate MMP-2 and MMP-9 in J774A.1 macrophages [41]. Ceramide and its phosphorylated counterpart are recognized as "bioactive sphingolipids" and they participate in signal transduction pathways, regulating various different cell functions such as proliferation, differentiation, adhesion and cell death [42]. The role of CIP in the increased expression/secretion of MMPs and in cell death in cutaneous and systemic loxoscelism will be further investigated.

We showed here that tetracycline significantly reduced renal injury in animals injected with the venom after $24 \mathrm{~h}$ of treatment, as demonstrated by a reduction in the histopathology and in the secretion markers of renal injury in urine and serum. The tetracycline group of antibiotics is increasingly being used for treatment of non-infectious diseases because of its effect on metalloprotease synthesis and activity. Several studies have demonstrated the role of MMPs in renal injury, including that caused by ischemia reperfusion (I/R) [18-20,36,37]. In addition, several studies demonstrated that doxycycline and minocycline inhibited MMP-2 and MMP-9 expression in animal models of ischemia reperfusion injury and thereby reduced the pathology. In rats subjected to renal I/R, increased MMP-2 expression was reduced by tetracycline, which also reduced apoptosis $[19,20,36]$. Our observation that tetracycline can inhibit the Loxosceles venom induced renal pathology, suggests that tetracyclines could be used in the treatment of renal pathology in systemic loxoscelism.

Serum and urine were collected from animals injected with venom and/or tetracycline for evaluation of the presence of protein, albumin, creatinine and urea, as indication of renal injury [43]. Loxosceles venom induced a significant increase in creatinine and protein secretion into the urine and generation of urea in the serum, which was largely prevented by the administration of tetracycline. However, while the venom also induced a significant decrease in serum albumin levels this was not prevented by tetracycline. Reduced levels of albumin can be present in acute renal syndrome. This can be related to the inflammatory process, in which reduction of the albumin concentration in the circulation occurs due to a decrease of osmotic pressure by an increase of the reabsorption of sodium and water [44]. 


\section{Conclusions}

The data presented here, using in vitro and in vivo models, suggest that activation of MMP-2 and MMP-9 is involved in renal injury induced by Loxosceles venom and its main toxin SMases D and that the use of tetracycline may have a protective effect on Loxosceles venom and SMase D induced kidney damage and could potentially aid the treatment of systemic loxoscelism.

\section{Material and Methods}

\subsection{Chemicals, Reagents, and Buffers}

Tween 20, bovine serum albumin (BSA), formalin, gelatin, Triton X-100, 3-(4,5 dimethylthiazol2yl)-2,5 diphenyltetrazolium bromide-MTT and tetracycline were from Sigma (St. Louis, MO, USA). Brij-35 was from Fluka-BioChemika (Werdenberg, Switzerland). Coomassie brilliant blue solution: $40 \%$ methanol, $10 \%$ acetic acid and $0.1 \%$ Coomassie brilliant blue. Buffers were: Phosphate-Buffered Saline (PBS), pH 7.2, containing $10 \mathrm{mM} \mathrm{NaH}_{2} \mathrm{PO}_{4}, 150 \mathrm{mM} \mathrm{NaCl}$; Zymography buffer, pH 8.3: $50 \mathrm{mM}$ Tris- $\mathrm{HCl}, 200 \mathrm{mM} \mathrm{NaCl}, 10 \mathrm{mM} \mathrm{CaCl}_{2}, 0.05 \%$ Brij-35.

\subsection{Venom}

Loxosceles intermedia spiders were provided by "Laboratório de Imunoquímica, Instituto Butantan, SP, Brazil". The venom was obtained by electrostimulation by the method of Bucherl [45], with slight modifications. Briefly, 15-20 V electrical stimuli were repeatedly applied to the spider sternum and the venom drops were collected with a micropipette, aliquoted and stored at $-20{ }^{\circ} \mathrm{C}$. The permission to access the Loxosceles venom (permission No. 01/2009) was provided by the Brazilian Institute of Environment and Renewable Natural Resources (IBAMA), a Brazilian Ministry of the Environment's enforcement agency.

\subsection{Sphingomyelinase D Expression}

Recombinant L. intermedia SMase D named as P1 (accession number: AY304471.2) was expressed in Escherichia coli strain BL21 (DE3), as a fusion protein composed of the mature SMase D with a N-terminal extension containing a $6 \times$ histidine tag, and purified as described [46]. The protein content of the samples was evaluated by the Lowry method [47].

\subsection{Cell Culture and Maintenance}

The human kidney cell line HK-2 [48] was maintained in 50\% DMEM and 50\% RPMI-1640 medium (Gibco-BRL, Gaithersburg, MD, USA), supplemented with $10 \%$ fetal bovine serum (FBS), $100 \mathrm{IU} / \mathrm{mL}$ penicillin and streptomycin at $37^{\circ} \mathrm{C}$ in humidified air with $5 \% \mathrm{CO}_{2}$.

\subsection{Cell Viability}

Cell viability was analyzed by the MTT [49] assay with slight modifications. Briefly, HK-2 cells were sub-cultured in 96-well plates in fetal bovine serum (FBS) containing culture medium at $5 \times 10^{4}$ cells $/ 200 \mu \mathrm{L}$. After $24 \mathrm{~h}$, the cells were maintained overnight in culture medium without FBS and then incubated with different concentrations of Loxosceles venom or SMase D in the presence or absence of increasing concentrations of tetracycline. Cells incubated with medium plus PBS were used as positive control (100\% viable). After the indicated periods of incubation $(24,48,72 \mathrm{~h})$, the culture supernatants were removed and the cells were incubated with $60 \mu \mathrm{L} /$ well of MTT solution in medium and the plates incubated for $30 \mathrm{~min}$ at $37{ }^{\circ} \mathrm{C} / 5 \% \mathrm{CO}_{2}$. Supernatants were removed and replaced with $100 \mu \mathrm{L}$ of DMSO. The absorbance of the samples was measured in a spectrophotometer (Multiskan-EX, Labsystems, Finland) at 540 and $620 \mathrm{~nm}$. The relative cell viability was calculated as:

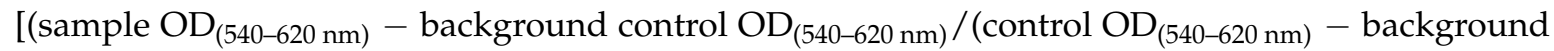
$\left.\mathrm{OD}_{(540-620 \mathrm{~nm})}\right] \times 100$. 


\subsection{Caspase-3 Activity Assay}

Apoptosis was assessed using the Caspase- 3 kit according to the manufacturer's recommendations (Roche Molecular Biochemicals, Pleasanton, CA, USA). Briefly, HK-2 cells treated with venom or SMase $\mathrm{D}\left(10 \mu \mathrm{g} / 10^{6}\right.$ cells $)$, for $2 \mathrm{~h}$ at $37^{\circ} \mathrm{C}$, were lysed with the lysis buffer and centrifuged for $1 \mathrm{~min}, 20^{\circ} \mathrm{C}$ at $14,000 \mathrm{rpm}$. The supernatant was removed and stored at $-20{ }^{\circ} \mathrm{C}$ until use. 96-well plates were sensitized with anti-caspase- 3 monoclonal antibody and incubated at $4{ }^{\circ} \mathrm{C}$ overnight. Blocking solution was added to all wells and the plates were incubated for $30 \mathrm{~min}$ at room temperature. The plates were washed with wash solution and $100 \mu \mathrm{L}$ of each experimental sample were added and the plates were incubated for $1 \mathrm{~h}$ at $37^{\circ} \mathrm{C}$. The plates were washed, substrate solution (Ac-DEVD-AFC) was added to the wells and the plates were incubated at $37^{\circ} \mathrm{C}$. Activation of Caspase- 3 was determined after $3 \mathrm{~h}$ using a VICTOR3 ${ }^{\mathrm{TM}}$ spectrofluorimeter (Perkin-Elmer, Waltham, MA, USA), using excitation and emission wavelengths of $405 \mathrm{~nm} 535 \mathrm{~nm}$, respectively. The Caspase-3 activity was expressed as the amount of Caspase-3-induced release of the fluorescent AFC (7-amido-4-trifluoromethyl coumarin) per minute.

\subsection{Gelatin Zymography}

Supernatants from HK-2 cells incubated with venom or SMase D, in the presence or absence of tetracycline, were mixed with non-reducing sample buffer and run on SDS-PAGE (10\% polyacrylamide gel containing $1 \%$ gelatin) [50]. Gels were washed twice for $30 \mathrm{~min}$ at room temperature in $2.5 \%$ Triton $\mathrm{X}-100$, and incubated overnight at $37^{\circ} \mathrm{C}$ in zymography buffer. Gels were stained in Coomassie Brilliant Blue solution for analysis of the presence of clear zones, which indicates proteolytic digestion [51].

\subsection{RNA Extraction}

HK-2 cells were sub-cultured in 24-well plates in DMEM/RPMI medium plus FBS at $5 \times 10^{5} \mathrm{cell} / \mathrm{mL}$ at $24 \mathrm{~h}$. Subsequently, the cultures were maintained overnight in medium without FBS followed by incubation with venom $(12.5 \mu \mathrm{g})$ or SMase D $(6.25 \mu \mathrm{g})$ in the presence or absence of tetracycline at $37^{\circ} \mathrm{C} / 5 \% \mathrm{CO}_{2}$. After $48 \mathrm{~h}$, total RNA was extracted from the cells using RNAspin Mini RNA Isolation kit (GE Healthcare, Pittsburgh, PA, USA). The RNA was aliquoted and stored at $-80^{\circ} \mathrm{C}$ until use.

\subsection{RT-PCR and PCR}

RNA samples were subjected to reverse transcription reaction using the Super Script Plasmid System for cDNA Synthesis (Invitrogen Carlsbad, CA, USA) to obtain the cDNA, according to manufacturer's instructions. The transcribed cDNA was then amplified by PCR using the following primers for MMP-2 (sense: 5'-CAC CTA TAC CAA GAA CTT CCG-3' ${ }^{\prime}$, anti-sense: 5'-CAG GAG GAG AAG GCT GTG TT-3'), MMP-9 (sense: 5'-TGG ACG ATG CCT GCA ACG TG-3', anti-sense: $5^{\prime}$-GTC GTG CGT GTC CAA AGG CA-3') and $\beta$-actin (sense: $5^{\prime}$-CCT TCC TGG GCA TGG AGTC-3', anti-sense: $5^{\prime}$-GAG GAG CAA TGA TCT TGA TCT TC-3'). PCR products were analyzed on $2 \%$ agarose gel and specific bands were quantified by densitometry (Gel Logic 100, Kodak, Rochester, NY, USA).

\subsection{Mice}

BALB/c male mice, aged 2 months and weighing 18-22 g, were obtained from the Central Animal Breeding unit at the Butantan Institute, SP, Brazil. The animals had ad libitum access to water and food. All experimental procedures involving animals were in accordance with the ethical principles in animal research adopted by the Brazilian Society of Animal Science and the National Brazilian Legislation no.11.794/08. The protocol was approved by the Institutional Committee for the Care and Use of Laboratory Animals from Butantan Institute (CEUAIB 698-10). 


\subsection{Treatment of Mice with Loxosceles Venom and Tetracycline}

Mice (6 per group) were kept throughout the experiments in individual metabolic cages. Samples of $200 \mu \mathrm{L}$ of $L$. intermedia venom $(48 \mu \mathrm{g} / \mathrm{mL})$ in PBS were injected intradermally (i.d.) in the dorsal region of mice. Thirty minutes later, the animals were injected with $200 \mu \mathrm{L}$ of tetracycline $(5 \mathrm{mg} / \mathrm{mL})$ intraperitoneally (i.p.), which was repeated twice at $4 \mathrm{~h}$ intervals. Negative control groups were animals injected with PBS and treated as the experimental groups. After $24 \mathrm{~h}$, the mice were euthanized and the kidneys collected for histological analysis; serum and urine were also collected for biochemical analysis.

\subsection{Biochemical Analysis}

Urine and serum samples were collected from control and envenomed animals, treated or not with tetracycline, and analyzed for the presence of urea and albumin in serum samples collected after $24 \mathrm{~h}$, and creatinine and protein in urine samples collected during $24 \mathrm{~h}$, using specific kits (Labtest Diagnóstica SA, Minas Gerais, Brazil).

\subsection{Histological Analysis}

Twenty four hours after injection, the kidneys of animals were collected and fixed in $10 \%$ buffered formalin solution and embedded in paraffin. Tissue sections were stained with hematoxylin and eosin and examined for the presence of bleeding and tissue damage. Analysis of the degree of interstitial changes were estimated as 0: minimum, 1: tubular injuries were $<25 \%, 2: 25 \%-50 \%, 3: 50 \%-75 \%$, 4: $75 \%$; degree of pathological changes in the glomeruli were estimated: $0:$ minimum, $1:<10 \%$, 2: $10 \%-30 \%, 3: 30 \%-60 \%, 4: 60 \%$

\subsection{Statistical Analysis}

The results were expressed as the mean \pm SD. Data were analyzed statistically by the ANOVA and Tukey test in the in vitro assays. $p$-values $\leq 0.05,0.1$ and 0.001 were considered significant. In vivo assay data were analyzed statistically by the Kruskal-Wallis and F test. Statistical analyses were performed using GraphPad Prism software (version 7, La Jolla, CA, USA).

Acknowledgments: This work was supported by funds from Fundação de Amparo à Pesquisa do Estado de São Paulo, Brazil (FAPESP), CeTICS Program FAPESP (2013/07467-1) and Conselho Nacional de Desenvolvimento Científico e Tecnológico, Brazil (CNPq).

Author Contributions: Conceived and designed the experiments: C.K.O., M.M., C.W.v.d.B., D.V.T. Performed the experiments: C.K.O. Analysed the data: C.K.O., M.M., C.W.v.d.B., D.V.T. Contributed with reagents/materials: R.M.G.-d.A., D.V.T. Wrote the paper: C.K.O., M.M., C.W.v.d.B., D.V.T.

Conflicts of Interest: The authors declare no conflict of interest.

\section{References}

1. Sistema de Informação Agravos de Notificação (SINAN). Ministério da Saúde (BR). 2015. Available online: http:/ / portal.saude.gov.br/portal/saude (accessed on 26 April 2016).

2. Futrell, J. Loxoscelism. Am. J. Med. 1992, 304, 261-267. [CrossRef]

3. Ministério da Saúde. Manual de Acidentes por Animais Peçonhentos; Fundação Nacional da Saúde: Brasília, Brasil, 2001.

4. Silva, P.H.; Silveira, R.B.; Appel, M.H.; Mangili, O.C.; Gremski, W.; Veiga, S.S. Brown spiders and loxoscelism. Toxicon 2004, 44, 693-709. [CrossRef] [PubMed]

5. Schenone, H. Cutaneous loxoscelism with edematous predominance. Bol. Chil. Parasitol. 1998, 53, 78-83. [PubMed]

6. Fernandes-Pedrosa, M.F.; Junqueira-de-Azevedo, I.L.; Gonçalves-de-Andrade, R.M.; Kobashi, L.S.; Almeida, D.D.; Ho, P.L.; Tambourgi, D.V. Transcriptome analysis of Loxosceles laeta (Araneae, Sicariidae) spider venomous gland using expressed sequence tags. BMC Genom. 2008, 9. [CrossRef] [PubMed]

7. Tambourgi, D.V.; Gonçalves-de-Andrade, R.M.; van den Berg, C.W. Loxoscelism: From basic research to the proposal of new therapies. Toxicon 2010, 56, 1113-1119. [CrossRef] [PubMed] 
8. Forrester, L.J.; Barrett, J.T.; Campbell, B.J. Red blood cell lysis induced by the venom of the brown recluse spider: The role of sphingomyelinase D. Arch. Biochem. Biophys. 1978, 187, 355-365. [CrossRef]

9. Kurpiewski, G.; Forrester, L.J.; Barrett, J.T.; Campbell, B.J. Platelet aggregation and sphingomyelinase D activity of a purified toxin from the venom of Loxosceles reclusa. Biochim. Biophys. Acta 1981, 678, 467-476. [CrossRef]

10. Tambourgi, D.V.; Magnoli, F.C.; van den Berg, C.W.; Morgan, B.P.; de Araújo, P.S.; Alves, E.W.; da Silva, W.D. Sphingomyelinases in the venom of the spider Loxosceles intermedia are responsible for both dermonecrosis and complement-dependent hemolysis. Biochem. Biophys. Res. Commun. 1998, 251, 366-373. [CrossRef] [PubMed]

11. Rivera, I.G.; Ordoñez, M.; Presa, N.; Gomez-Larrauri, A.; Simón, J.; Trueba, M.; Gomez-Muñoz, A. Sphingomyelinase D/ceramide 1-phosphate in cell survival and inflammation. Toxins 2015, 7, 1457-1466. [CrossRef] [PubMed]

12. Van Meeteren, L.A.; Frederiks, F.; Giepmans, B.N.; Pedrosa, M.F.; Billington, S.J.; Jost, B.H.; Tambourgi, D.V.; Moolenaar, W.H. Spider and bacterial sphingomyelinases D target cellular lysophosphatidic acid receptors by hydrolyzing lysophosphatidylcholine. J. Biol. Chem. 2004, 279, 10833-10836. [CrossRef] [PubMed]

13. Moolenaar, W.H. Bioactive lysophospholipids and their G protein-coupled receptors. Exp. Cell Res. 1999, 253, 230-238. [CrossRef] [PubMed]

14. Ye, X.; Ishii, I.; Kingsbury, M.A.; Chun, J. Lysophosphatidic acid as a novel cell survival/apoptotic factor. Biochim. Biophys. Acta 2002, 1585, 108-113. [CrossRef]

15. Tambourgi, D.V.; Paixão-Cavalcante, D.; Gonçalves-de-Andrade, R.M.; Fernandes-Pedrosa, M.; Magnoli, F.C.; Morgan, B.P.; van den Berg, C.W. Loxosceles sphingomielinase induces complement-dependent dermonecrosis, neutrophil infiltration and endogenous gelatinase expression. J. Investig. Dermatol. 2005, 124, 725-731. [CrossRef] [PubMed]

16. Paixão-Cavalcante, D.; van den Berg, C.W.; Fernandes-Pedrosa, M.; Gonçalves-de Andrade, R.M.; Tambourgi, D.V. Role of matrix metalloproteinases in HaCat keratinocytes apoptosis induced by Loxosceles venom sphingomyelinase D. J. Investig. Dermatol. 2006, 126, 61-68. [CrossRef] [PubMed]

17. Paixão-Cavalcante, D.; van den Berg, C.W.; Gonçalves-de-Andrade, R.M.; Fernandes-Pedrosa, M.; Okamoto, C.K.; Tambourgi, D.V. Tetracycline protects against dermonecrosis induced by Loxosceles spider venom. J. Investig. Dermatol. 2007, 127, 1410-1418. [CrossRef] [PubMed]

18. Basile, D.P.; Fredrich, K.; Weihrauch, D.; Hattan, N.; Chilian, W.M. Angiostatin and matrix metalloprotease expression following ischemic acute renal failure. Am. J. Physiol. Renal Physiol. 2004, 286, F893-F902. [CrossRef] [PubMed]

19. Du, X.; Shimizu, A.; Masuda, Y.; Kuwahara, N.; Arai, T.; Kataoka, M.; Uchiyama, M.; Kaneko, T.; Akimoto, T.; Iino, Y.; et al. Involvement of matrix metalloproteinase-2 in the development of renal interstitial fibrosis in mouse obstructive nephropathy. Lab. Investig. 2012, 92, 1149-1160.

20. Sutton, T.A.; Kelly, K.J.; Mang, H.E.; Plotkin, Z.; Sandoval, R.M.; Dagher, P.C. Minocycline reduces renal microvascular leakage in a rat model of ischemic renal injury. Am. J. Physiol. Renal Physiol. 2005, 288, F91-F97. [CrossRef] [PubMed]

21. Murphy, G.; Stanton, H.; Cowell, S.; Butler, G.; Kñauper, V.; Atkinson, S.; Gavrilovic, J. Mechanism for pro matrix metalloproteinase activation. APMIS 1999, 107, 38-44. [CrossRef] [PubMed]

22. Castro, M.M.; Kandasamy, A.D.; Youssef, N.; Schulz, R. Matrix metalloproteinase inhibitor properties of tetracyclines: Therapeutic potential in cardiovascular diseases. Pharmacol. Res. 2011, 64, 551-560.

23. Ataie-Kachoie, P.; Morris, D.L.; Pourgholami, M.H. Minocycline suppresses interleukine-6, its receptor system and signaling pathways and impairs migration, invasion and adhesion capacity of ovarian cancer cells: In vitro and in vivo studies. PLoS ONE 2013, 8. [CrossRef] [PubMed]

24. Schwartz, J.; Holmuhamedov, E.; Zhang, X.; Lovelace, G.L.; Smith, C.D.; Lemasters, J.J. Minocycline and doxycycline, but not other tetracycline-derived compounds, protect liver cells from chemical hypoxia and ischemia/reperfusion injury by inhibition of the mitochondrial calcium uniporter. Toxicol. Appl. Pharmacol. 2013, 273, 172-179. [CrossRef] [PubMed]

25. Acharya, M.R.; Venitz, J.; Figg, W.D.; Sparreboom, A. Chemically modified tetracyclines as inhibitors of matrix metalloproteinases. Drug Resist. Updates 2004, 7, 195-208. [CrossRef] [PubMed] 
26. Tambourgi, D.V.; Petricevich, V.L.; Magnoli, F.C.; Assaf, S.L.; Jancar, S.; da Silva, W.D. Endotoxemic-like shock induced by Loxosceles spider venoms: Pathological changes and putative cytokine mediators. Toxicon 1998, 36, 391-403.

27. Luciano, M.N.; da Silva, P.H.; Chaim, O.M.; dos Santos, V.L.; Franco, C.R.; Soares, M.F.; Zanata, S.M.; Mangili, O.C.; Gremski, W.; Veiga, S.S. Experimental evidence for a direct cytotoxicity of Loxosceles intermedia (brown spider) venom in renal tissue. J. Histochem. Cytochem. 2004, 52, 455-467. [CrossRef] [PubMed]

28. Lung, J.M.; Mallory, S.B. A child with spider bite and glomerulonephritis: A diagnostic challenge. Int. J. Dermatol. 2000, 39, 287-289. [CrossRef] [PubMed]

29. Chaim, O.M.; Sade, Y.B.; da Silveira, R.B.; Toma, L.; Kalapothakis, E.; Chavez-Olórtegui, C.; Mangili, O.C.; Gremski, W.; von Dietrich, C.P.; Nader, H.B.; et al. Brown spider dermonecrotic toxin directly induces nephrotoxicity. Toxicol. Appl. Pharmacol. 2006, 211, 64-77. [CrossRef] [PubMed]

30. Kusma, J.; Chaim, O.M.; Wille, A.C.; Ferrer, V.P.; Sade, Y.B.; Donatti, L.; Gremski, W.; Mangili, O.C.; Veiga, S.S. Nephrotoxicity caused by brown spider venom phospholipase D (dermonecrotic toxin) depends on catalytic activity. Biochimie 2008, 90, 11-12. [CrossRef] [PubMed]

31. Lucato, R.V., Jr.; Abdulkader, R.C.; Barbaro, K.C.; Mendes, G.E.; Castro, I.; Baptista, M.A.; Cury, P.M.; Malheiros, D.M.; Schor, N.; Yu, L.; et al. Loxosceles gaucho venom-induced acute kidney injury-In vivo and in vitro studies. PLoS Negl. Trop. Dis. 2011, 5, 1-5. [CrossRef] [PubMed]

32. Ribeiro, R.O.; Chaim, O.M.; da Silveira, R.B.; Gremski, L.H.; Sade, Y.B.; Paludo, K.S.; Senff-Ribeiro, A.; de Moura, J.; Chavez-Olórtegui, C.; Gremski, W.; et al. Biological e structural comparison of recombinant phospholipase D toxins from Loxosceles intermedia (brown spider) venom. Toxicon 2007, 50, 1162-1174. [CrossRef] [PubMed]

33. Birkedal-Hansen, H.; Moore, W.G.; Bodden, M.K.; Windsor, L.J.; Birkedal-Hansen, B.; de Carlo, A.; Engler, J.A. Matrix metalloproteinases: A review. Crit. Rev. Oral Biol. Med. 1993, 4, 197-250. [CrossRef] [PubMed]

34. Visse, R.; Nagase, H. Matrix metalloproteinases and tissue inhibitors of metalloproteinases: Structure, function and biochemistry. Circ. Res. 2003, 92, 827-839. [CrossRef] [PubMed]

35. Verma, R.P.; Hansch, C. Matrix metalloproteinases (MMPs): Chemical-biological functions and (Q)SARs. Bioorg. Med. Chem. 2007, 15, 2223-2268. [CrossRef] [PubMed]

36. Kucuk, K.; Kabadere, S.; Tosun, M.; Koken, T.; Kinaci, M.K.; Isikli, B.; Erkasap, N. Protective effects of doxycycline in ischemia/reperfusion injury on kidney. J. Phisiol. Biochem. 2009, 65, 183-191. [CrossRef]

37. Zhao, H.; Dong, Y.; Tian, X.; Tan, T.K.; Liu, Z.; Zhang, Y.; Harris, D.C.; Zheng, G. Matrix metalloproteinases contribute to kidney fibrosis in chronic kidney diseases. World J. Nephrol. 2013, 6, 84-89. [CrossRef] [PubMed]

38. Nee, L.E.; McMorrow, T.; Campbell, E.; Slattery, C.; Ryan, M.P. TNF-alpha and IL-1 beta-mediated regulation of MMP-9 and TIMP-1 in renal proximal tubular cells. Kidney Int. 2004, 66, 1376-1386. [CrossRef] [PubMed]

39. Liu, Q.A.; Hengartner, M.O. The molecular mechanism of programmed cell death in C. elegans. Ann. N. Y. Acad. Sci. 1999, 887, 92-104. [CrossRef] [PubMed]

40. Meier, P.; Finch, A.; Evan, G. Apoptosis in development. Nature 2000, 407, 796-801. [CrossRef] [PubMed]

41. Ordoñez, M.; Rivera, I.G.; Presa, N.; Gomez-Muñoz, A. Implication of matrix metalloproteinases 2 and 9 in ceramide 1-phosphate-stimulated macrophage migration. Cell Signal. 2016, 28, 1066-1074. [CrossRef] [PubMed]

42. Zhou, K.; Blom, T. Trafficking and functions of bioactive sphingolipids: Lessons from cells and model membranes. Lipid Insights 2015, 8 (Suppl. 1), 11-20. [PubMed]

43. Schrier, R.W.; Wang, W.; Poole, B.; Mitra, A. Acute renal failure: Definitions, diagnosis, pathogenesis, and therapy. J. Clin. Investig. 2004, 114, 5-14. [CrossRef] [PubMed]

44. Don, B.R.; Kaysen, G. Serum albumin: Relationship to inflammation and nutrition. Semin. Dial. 2004, 17, 432-437. [CrossRef] [PubMed]

45. Bucherl, W. Biology and venoms of the most important South American spiders of the genera Phoneutria, Loxosceles, Lycosa, and Latrodectus. Am. Zool. 1969, 9, 157-159. [CrossRef] [PubMed]

46. Tambourgi, D.V.; Fernandes-Pedrosa, M.F.; van den Berg, C.W.; Gonçalves-de-Andrade, R.M.; Ferracini, M.; Paixão-Cavalcante, D.; Morgan, B.P.; Rushmere, N.K. Molecular cloning, expression, function and immunoreactivities of members of a gene family of sphingomyelinases from Loxosceles venom glands. Mol. Immunol. 2004, 41, 831-840. [CrossRef] [PubMed]

47. Lowry, O.H.; Rosebrough, N.J.; Farr, A.L.; Randall, R.J. Protein measurement with the Folin phenol reagent. J. Biol. Chem. 1951, 193, 265-275. [PubMed] 
48. Ryan, M.J.; Johnson, G.; Kirk, J.; Fuerstenberg, S.M.; Zager, R.A.; Torok-Storb, B. HK-2: An immortalized proximal tubule epithelial cell line from normal adult human kidney. Kidney Int. 1994, 45, 48-57. [CrossRef] [PubMed]

49. Mosmann, T. Rapid colorimetric assay for cellular growth and survival: Application to proliferation and cytotoxicity assays. J. Immunol. Methods 1983, 65, 55-63. [CrossRef]

50. Laemmli, U.K. Cleavage of structural proteins during the assembly of the head of bacteriophage T4. Nature 1970, 227, 680-685. [CrossRef] [PubMed]

51. Kleiner, D.E.; Stetler-Stevenson, W.G. Quantitative zymography: Detection of picogram quantities of gelatinases. Anal. Biochem. 1994, 218, 325-329. [CrossRef] [PubMed]

(C) 2017 by the authors. Licensee MDPI, Basel, Switzerland. This article is an open access article distributed under the terms and conditions of the Creative Commons Attribution (CC BY) license (http:/ / creativecommons.org/licenses/by/4.0/). 